\title{
Analisis Sistem Pembumian untuk Mengamankan Instalasi Listrik di Program Studi Teknik Elektro Fakultas Teknik Universitas Udayana Jimbaran Bali
}

\author{
Kadek Rudi Andika Setyawan ${ }^{1}$, I Gusti Ngurah Janardana ${ }^{2}$, Ngakan Putu Satriya Utama ${ }^{3}$
}

\begin{abstract}
Every building's electrical panel supposed to be connected with the grounding system, so that the Electrical installations, equipment and people inside the building could be spare from current or over voltage. The research was conducted to determine the characteristics of the grounding system (single rod, multiple rod $s<L$ and $s>L$, grid and plate) with the resistance value $\leq 5 \Omega$, which could securing the electric installation Electrical Engineering Department of Udayana University.

The research concluded that the grounding system which used in the Electrical Engineering Department of Udayana University Jimbaran Bali is a single rod type with ground resistance value 28 $\Omega$. The value of the ground resistance does not qualify the requirements value $\leq 5 \Omega$. The recommended ground system was installed with the ground resistance value in accordance with the requirements specified is a grid type ground system with ground resistance $4.79 \Omega$ or plate type ground system with the ground resistance $4.56 \Omega$, because the installation of the grid type or plate type grounding system is not as deep as the single rod type, multiple rod $s<L$ and multiple rod $s>L$, considering the limestone rock soil type.
\end{abstract}

Intisari- Setiap panel listrik bangunan gedung harus terkoneksi dengan sistem pembumian, agar instalasi listrik, peralatan dan manusia yang berada pada bangunan tersebut dapat terhindar dari bahaya arus atau tegangan lebih. Penelitian dilakukan untuk mengetahui karakteristik sistem pembumian (single rod, multiple rod $s<L$ dan $s>L$, grid dan plate) dengan nilai resistansi $\leq 5 \Omega$, yang dapat mengamankan instalasi listrik di Program Studi Teknik Elektro Universitas Udayan.

Berdasarkan hasil penelitian yang telah dilakukan, sistem pembumian yang digunakan di Program Studi Teknik Elektro Fakultas Teknik Universitas Udayana Jimbaran Bali adalah tipe single rod dengan nilai resistansi pembumiannya $28 \Omega$. Besar nilai resistansi pembumian tersebut belum memenuhi syarat yang ditetapkan sebasar $\leq 5 \Omega$

Sistem pembumian yang direkomendasikan dipasang dengan

${ }^{1}$ Mahasiswa, Program Studi Teknik Elektro Fakultas Teknik Universitas Udayana, Jln. Kampus Udayana Bukit Jimbaran, Bali 80361 INDONESIA (telp: 087762650059; fax: 0361-4321 e-mail; kadekrudiandika@gmail.com)

${ }^{2}$ Dosen, Program Studi Teknik Elektro Fakultas Teknik Universitas Udayana, Jln. Kampus Udayana Bukit Jimbaran, Bali 80361 INDONESIA (telp: 081338718182; fax: 0361-4321; e-mail: janarnada@ee.unud.ac.id)

${ }^{3}$ Dosen Program Studi Teknik Elektro Fakultas Teknik Universitas Udayana, Jln. Kampus Udayana Bukit Jimbaran, Bali 80361 INDONESIA (telp: 08113811221; fax: 0361-4321; e-mail: ngakansatriya@ee.unud.ac.id)

nilai resistansi pembumian sesuai dengan syarat yang ditetapkan adalah sistem pembumian tipe grid dengan resistansi pembumian sebesar 4,79 $\Omega$ atau system pembumian tipe plate dengan resistansi pembumian $4,56 \Omega$, karena pemasangan sistem pembumian tipe grid atau plate tidak terlalu dalam dibandingkan tipe single rod, multiple rod $s<L$ dan multiple rod $s>L$, mengingat tekstur tanah berbatu kapur.

Kata Kunci-Arus Dan Tegangan Lebih, Instalasi Listrik, Sistem Pembumian

\section{Pendahuluan}

Program Studi Teknik Elektro Fakultas Teknik Universitas Udayana Jimbaran Bali berlokasi dikawasan perbukitan dengan tekstur tanah berbatu kapur dengan nilai tahanan jenis tanah sebesar 256,224 $\Omega$-meter. Setiap panel listrik bangunan gedung yang ada di Program Studi Teknik Elektro Fakultas Teknik Universitas Udayana Jimbaran Bali harus memiliki dan terkoneksi dengan sistem pembumian, agar instalasi listrik, peralatan dan manusia yang berada pada bangunan tersebut dapat terhindar dari bahaya arus atau tegangan lebih. Dengan adanya sistem pembumian arus gangguan akan dialirkan ke tanah atau dibumikan sehingga tidak menyebabkan kerusakan pada instalasi listrik, peralatan serta manusia yang ada didalam bangunan tersebut [1].

Panel listrik Program Studi Teknik Elektro Fakultas Teknik Universitas Udayana Jimbaran Bali terkoneksi dengan sistem pembumian dengan besar nilai resistansi pembumian 28,5 $\Omega$ pada panel MDP (Main Distribution Panel) (hasil pengukuran 25 Maret 2017). Agar terhindar dari bahaya sambaran petir dibutuhkan nilai resistansi pembumian sebesar $\leqslant 5 \Omega$ [2]. Agar terhindar dari bahaya sambaran petir yang dapat menyebabkan kerusakan, nilai resistansi dari sistem pembumian membutuhkan harus sesuai dengan syarat yang telah ditetapkan. Nilai resistansi pembumian dipengaruhi oleh beberapa foktor seperti: jenis tanah, kadar air dalam tanah, temperatur tanah, kelembaban tanah, kandungan elektrolit tanah dan lain-lainnya [3].

Proses pengambilan data dengan tujuan mendapatkan datadata penunjang untuk penelitian dilakukan diarea Program Studi Teknik Elektro Fakultas Teknik Universitas Udayana Jimbaran Bali pada bulan Juli sampai September 2016. Penelitian dilakukan untuk mengetahui karakteristik sistem pembumian (single rod, multiple rod $s<L$, multiple rod $s>L$, grid dan plate) dengan nilai resistansi pembumian $\leqslant 5 \Omega$ dan dapat digunakan sebagai referensi sistem pembumian yang akan digunakan di Program Studi Teknik Elektro Fakultas Teknik Universitas Udayana Jimbaran Bali. Metode yang digunakan yaitu: mengumpulkan data tahanan jenis tanah $(\rho)$ dilokasi Program Studi Teknik Elektro Fakultas Teknik Universitas Udayana, menghitung resistansi pembumian 
berdasarkan data hasil pengukur tahanan jenis tanah $(\rho)$, menganalisis karakteristik sistem pembumian dengan tahanan jenis tanah $(\rho)$ sesuai dengan syarat $R \leqslant 5 \Omega$ dengan metode single rod, multiple rod $s<L$ dan $s>L$, plate dan grid.

\section{SISTEM PEMBUMIAN}

\section{A. Sistem Pembumian}

Sistem pembumian adalah faktor penting untuk pengamanan sistem tenaga listrik saat terjadinya gangguan arus atau tegangan lebih. Saat terjadi gangguan pada sistem tenaga listrik, dengan adanya sistem pembumian arus gangguan akan dialirkan ke dalam tanah atau dibumikan dan disebarkan ke segala arah [4]. Sistem pembumian merupakan sistem hubungan penghantar yang menghubungkan badan peralatan dan instalasi listrik dengan bumi sehingga dapat mengamankan manusia, peralatan atau instalasi listrik dari bahaya sengatan listrik ataupun arus dan tegangan lebih [5]. Fungsi pembumian yaitu untuk mengalirkan arus gangguan ke dalam tanah melalui suatu elektroda pembumian yang ditanam dalam tanah bila terjadi gangguan, untuk itu nilai resistansi dari sistem pembumian harus sesuai dengan syarat yang ditetapkan [6]. Semakin kecil nilai resistansi pembumian semakin bagus, tetapi nilai resistansi pembumian dipengaruhi oleh beberapa foktor seperti: jenis tanah, kadar air dalam tanah, temperatur tanah, kelembaban tanah, kandungan elektrolit tanah dan lain-lainnya [3]. Agar terhindar dari sambaran petir nilai tahanan pembumiannya minimal $\leqslant 5 \Omega$ [2]. Tujuan pemasangan sistem pembumian yaitu [7]:

- Membatasi tegangan antara bagian-bagian peralatan yang tidak dialiri arus dengan tanah sampai pada suatu harga yang aman untuk semua kondisi operasi, baik kondisi normal ataupun saat terjadi gangguan.

- Memperoleh impedansi yang rendah serta sebagai jalan balik arus hubung singkat ketanah. Bila arus hubung singkat dipaksa mengalir melalui tanah dengan tahanan yang tinggi akan menimbulkan perbedaan potensial yang besar dan berbahaya.

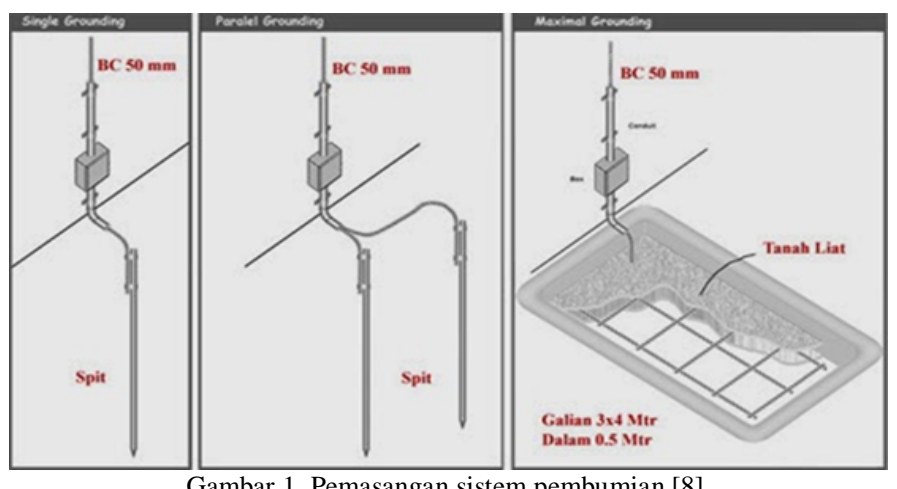

B. Sistem Pembumian Rod (grounding rod)

Grounding rod yaitu sitem pembumian dengan elektroda batang dari pipa besi atau besi baja yang dilapisi tembaga, dipancangkan dalam tanah secara tegak lurus [8].

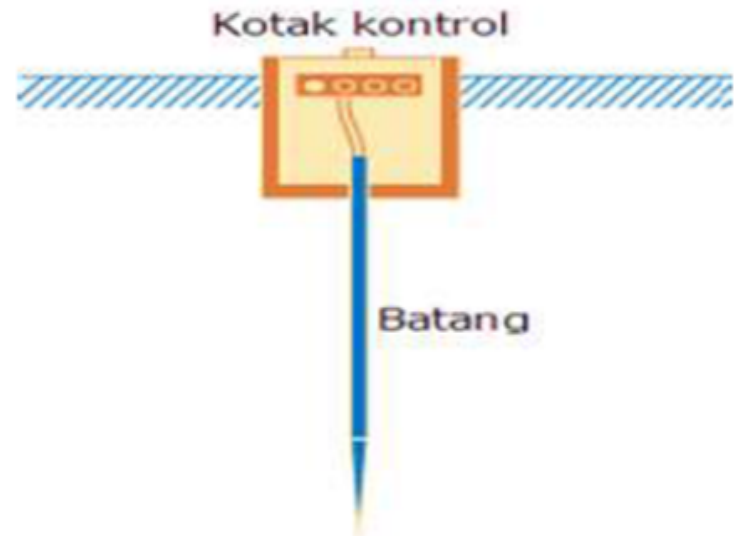

Gambar 2. Elektroda Batang rod [9]

1. Sistem pembumian single rod

Sistem pembumian single rod dapat dihitung menggunakan persamaan sebagai berikut [1]:

$$
R_{s r}=\frac{p}{2 \pi L} \ln \left(\frac{4 L}{a}-1\right)
$$

Keterangan:

$P=$ tahanan jenis tanah $(\Omega$-meter $)$

$\mathrm{L}=$ panjang elektroda pembumian (meter)

$a \quad$ = jari-jari elektroda pembumian (meter)

$R_{g r}=$ resistansi pembumian single $\operatorname{rod}(\Omega)$

2. Sistem pembumian multiple rod $s<L$

Sistem pembumian multiple rod $s<L$ dapat dihitung dengan persamaan sebagai berikut [3]:

$R_{M}=\frac{\rho}{4 \pi L}\left[\ln \frac{4 L}{a}+\ln \frac{4 L}{s}-2+\frac{s}{2 L}-\frac{g^{2}}{1 a^{2}}+\frac{s^{4}}{512 L^{4}}\right]$

Keterangan:

$\rho \quad=$ tahanan jenis tanah $(\Omega$-meter $)$

$\mathrm{s} \quad=$ jarak antar batang elektroda

$\mathrm{L}=$ panjang elektroda pembumian (meter)

a $\quad$ jari-jari elektroda pembumian (meter)

$\mathrm{R}_{\mathrm{M}}=$ resistansi pembumian multiple $\operatorname{rod} s<L(\Omega)$

3. Sistem pembumian multiple rod $s>L$

Sistem pembumian multiple rod $s>L$ dapat dihitung dengan persamaan sebagai berikut [3]:

$R_{m}=\frac{\rho}{4 \pi z}\left[\ln \frac{4 L}{a}-1\right]+\frac{\rho}{4 m s}\left[1-\frac{2^{2}}{g^{2}}+\frac{2 L^{4}}{5 x^{4}}\right]$

Keterangan:

$\rho \quad=$ tahanan jenis tanah $(\Omega$-meter $)$

$\mathrm{s} \quad=$ jarak antar batang elektroda

$\mathrm{L}=$ panjang elektroda pembumian (meter)

a $\quad$ jari-jari elektroda pembumian (meter)

$\mathrm{R}_{\mathrm{m}}=$ resistansi pembumian multiple $\operatorname{rod} s<L(\Omega)$

\section{Sistem Pembumian Grid}

Sistem pembumian grid digunakan bila sistem pembumian tipe mesh tidak dapat memberikan nilai resistansi pembumian yang diinginkan. Sehingga diambil solusi dengan menggunakan sistem pembumian tipe grid dengan menggabungkan sistem pembumian tipe mesh dan rod, 
bertujuan untuk mendapat nilai resistansi pembumian yang sesuai dengan syarat yang telah ditetapkan [10].

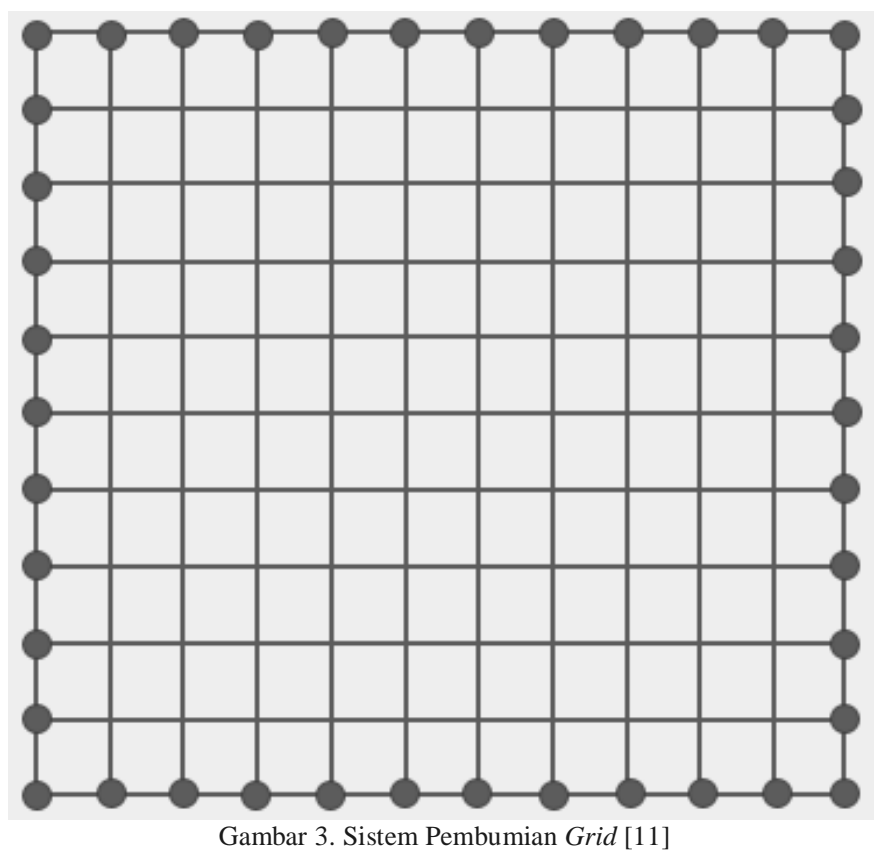

Sistem pembumian grid dapat dihitung menggunakan persamaan berikut [11]:

$$
R_{G}=\rho\left[\frac{1}{L_{1}+L_{2}}+\frac{1}{\sqrt{ } / 20 A}\left(1+\frac{1}{1+\hbar / 20 / A}\right)\right]
$$

Keterangan:

$$
\begin{array}{ll}
\rho & =\text { tahanan jenis tanah }(\Omega \text {-meter) } \\
\mathrm{h} & =\text { kedalaman penanaman konduktor grid (meter) } \\
\mathrm{L} & =\text { panjang total konduktor } \text { grid }(\text { meter }) \\
\mathrm{A} & =\text { luas area grid }\left(\text { meter }^{2}\right) \\
\mathrm{R}_{\mathrm{G}} & =\text { resistansi pembumian } \operatorname{grid}(\Omega)
\end{array}
$$

\section{Sistem Pembumian Plate}

Elektroda plate adalah elektroda dari bahan logam utuh atau berlubang. Elektroda plate ditanam tegak lurus dalam tanah, ukurannya disesuaikan dengan resistans pembumian yang diperlukan. Jika diperlukan untuk memperoleh resistans pembumian yang lebih rendah, maka jarak elektroda plate dapat diparalelkan sesuai dengan kebutuhan [12].

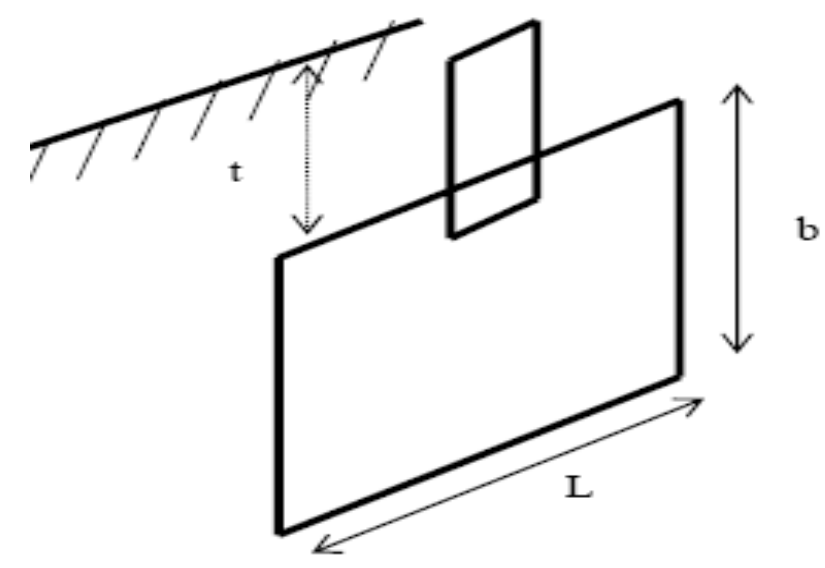

Gambar 4. Elektroda Plate [11]

Sistem pembumian tipe plate dapat dihitung menggunakan persamaan berikut [7]:

$$
R_{p}=\frac{\rho}{4,12}\left[\left(1+1,84 \frac{b}{t}\right)\right]
$$

Keterangan:

$$
\begin{array}{ll}
\rho & =\text { tahanan jenis tanah }(\Omega \text {-meter }) \\
\mathrm{t} & =\text { kedalaman penanaman }(\text { meter }) \\
\mathrm{L} & =\text { panjang plate }(\text { meter }) \\
\mathrm{b} & =\text { lebar plate }\left(\text { meter }^{2}\right) \\
\mathrm{Rp} & =\text { resistansi pembumian tipe plate }(\Omega)
\end{array}
$$

\section{METODE PENELITIAN}

Penelitian dilakukan di Program Studi Teknik Elektro Fakultas Teknik Universitas Udayana Jimbaran Bali dengan tujuan mendapatkan data-data penunjang untuk penelitian. Proses penelitian dimulai pada bulan Juli 2016. Sumber data yang digunakan berupa sumber data primer dan sekunder. Sumber data primer diperoleh dengan pengukuran tahanan tanah (R) secara langsung diarea penelitian dan sumber data sekunder diperoleh melalui sumber data kepustakaan (library research).

Pada proses pengukuran, alat yang digunakan adalah Ground Resistance Meter (GMR). GMR digunakaan untuk memperoleh data tahanan tanah (R). Pengukuran tahanan tanah $(R)$ untuk mendapatkan data tahanan jenis tanah $(\rho)$ menggunakan rumus $\rho=2 \pi a R$. Pengukuran dilakukan sebanyak 3 kali dalam sehari selama 11 hari. Setiap kali pengukuran nilai $\mathrm{R}$ tanah yang diambil adalah nilai $\mathrm{R}$ tanah terbesar. Alur analisis yang digunakan dalam penelitian ini adalah:

1. Mengumpulkan data tahanan tanah (R) diarea Program Studi Teknik Elektro Fakultas Teknik Universitas Udayana Jimbaran Bali.

2. Menghitung resistansi pembumian berdasarkan data hasil pengukur tahanan jenis tanah $(\rho)$ diarea Program Studi Teknik Elektro Fakultas Teknik Universitas Udayanaa Jimbaran Bali. 
3. Menganalisis karakteristik sistem pembumian dengan tahanan jenis tanah $(\rho)$ sesuai dengan syarat $R \leqslant 5 \Omega$ dengan metode yang digunakan (single rod, multiple rod $s<L$, multiple rod $s>L$, grid dan plate) dan kesimpulan.

\section{HASIL DAN PEMBAHASAN}

\section{A. Program Studi Teknik Elektro Fakultas Teknik Universitas} Udayana Jimbaran Bali

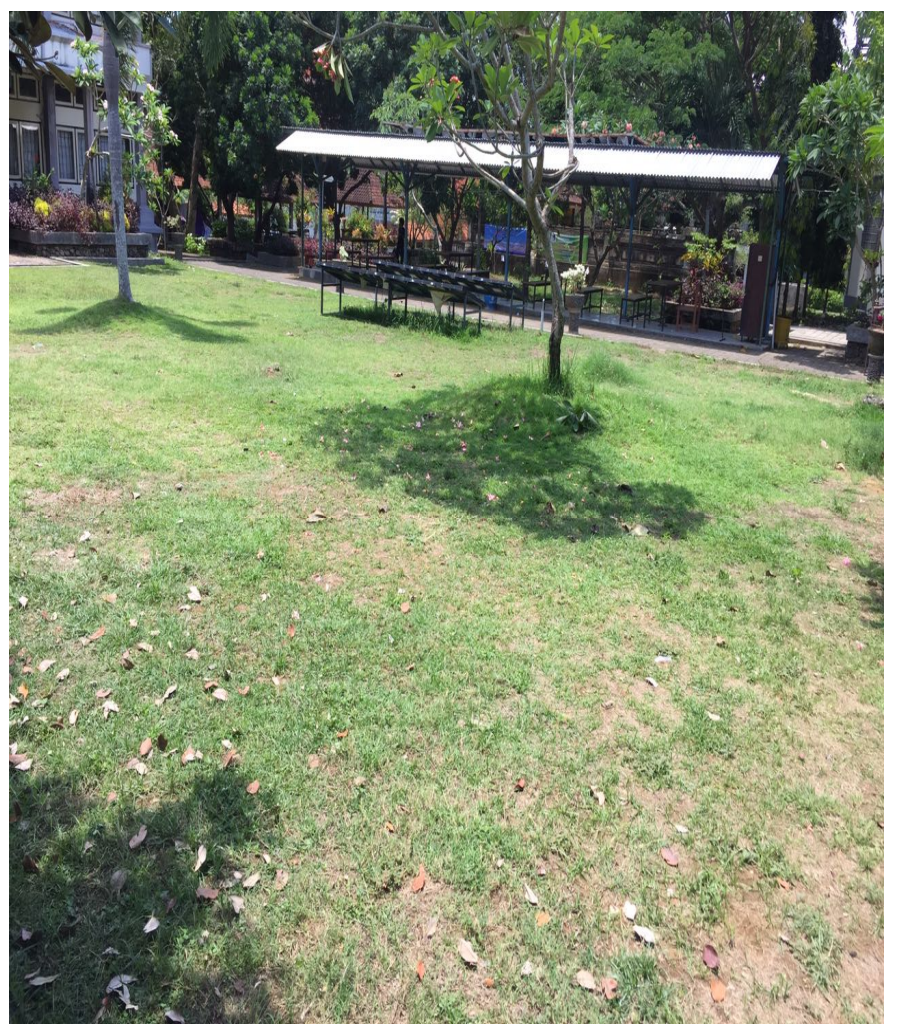

Gambar 5. Lokasi Pengukuran Tahanan Jenis Tanah $(\rho)$

Program Studi Teknik Elektro Fakultas Teknik Universitas Udayana terletak di Bukit Jimbaran dengan tekstur tanah berbatu kapur dan terdiri dari beberapa bangunan gedung, seperti bangunan untuk perkuliahan, laboratorium dan kantor. Panel listrik Program Studi Teknik Elektro Fakultas Teknik Universitas Udayana Jimbaran Bali terkoneksi dengan sistem pembumian dengan besar nilai resistansi pembumian 28,5 $\Omega$ pada panel MDP (Main Distribution Panel). Untuk mendukung pengoperasian di Program Studi Teknik Elektro Fakultas Teknik Universitas Udayana Jimbaran Bali, sumber daya listrik yang digunakan berasal dari PLN.

\section{B. Hasil Pengukuran Tahanan Tanah}

Hasil pengukuran tahanan tanah untuk mendapatkan nilai tahanan jenis tanah yang dilakukan diarea Program Studi Teknik Elektro Fakultas Teknik Universitas Udayana Jimbaran Bali selama 11 hari dapat dilihat pada tabel 1.
Tabel 1. HASIL PENGUKURAN TAHANAN TANAH DI LOKASI PENELITIAN

\begin{tabular}{|c|c|c|c|c|c|}
\hline No & $\begin{array}{c}\text { Hari } \\
\text { (tanggal) }\end{array}$ & $\begin{array}{l}\text { Pukul } \\
\text { (wita) }\end{array}$ & $\begin{array}{l}\mathrm{R} \\
(\Omega)\end{array}$ & $\begin{array}{c}\mathrm{a} \\
\text { (meter) }\end{array}$ & $\begin{array}{c}\rho(2 \pi \times a \times R) \\
(\Omega \text {-meter })\end{array}$ \\
\hline \multirow{3}{*}{1} & \multirow{3}{*}{$\begin{array}{c}\text { Senin } \\
(25-07- \\
2016)\end{array}$} & 09.00 & 1,12 & 20 & 140,672 \\
\hline & & 12.00 & 1,19 & 20 & 149,464 \\
\hline & & 15.00 & 1,19 & 20 & 149,464 \\
\hline \multirow{3}{*}{2} & \multirow{3}{*}{$\begin{array}{c}\text { Rabu } \\
(27-07- \\
2016)\end{array}$} & 09.00 & 1,21 & 20 & 151,976 \\
\hline & & 12.00 & 1,25 & 20 & 157 \\
\hline & & 15.00 & 1,25 & 20 & 157 \\
\hline \multirow{3}{*}{3} & \multirow{3}{*}{$\begin{array}{c}\text { Kamis } \\
(18-08- \\
2016)\end{array}$} & 09.00 & 1,8 & 20 & 226.08 \\
\hline & & 12.00 & 1,99 & 20 & 249,944 \\
\hline & & 15.00 & 1,99 & 20 & 249,944 \\
\hline \multirow{3}{*}{4} & \multirow{3}{*}{$\begin{array}{c}\text { Jumat } \\
\text { (19-08- } \\
2016)\end{array}$} & 09.00 & 2,00 & 20 & 251.2 \\
\hline & & 12.00 & 2,04 & 20 & 256,224 \\
\hline & & 15.00 & 2,04 & 20 & 256,224 \\
\hline \multirow{3}{*}{5} & \multirow{3}{*}{$\begin{array}{c}\text { Sabtu } \\
(27-08- \\
2016)\end{array}$} & 09.00 & 2,04 & 20 & 256,224 \\
\hline & & 12.00 & 2,04 & 20 & 256,224 \\
\hline & & 15.00 & 2,04 & 20 & 256,224 \\
\hline \multirow{3}{*}{6} & \multirow{3}{*}{$\begin{array}{c}\text { Minggu } \\
(28-08- \\
2016)\end{array}$} & 09.00 & 2,04 & 20 & 256,224 \\
\hline & & 12.00 & 2,04 & 20 & 256,224 \\
\hline & & 15.00 & 2,04 & 20 & 256,224 \\
\hline \multirow{3}{*}{7} & \multirow{3}{*}{$\begin{array}{c}\text { Kamis } \\
(1-09-2016)\end{array}$} & 09.00 & 2,04 & 20 & 256,224 \\
\hline & & 12.00 & 2,04 & 20 & 256,224 \\
\hline & & 15.00 & 2,04 & 20 & 256,224 \\
\hline \multirow{3}{*}{8} & \multirow{3}{*}{$\begin{array}{c}\text { Jumat } \\
(2-09-2016)\end{array}$} & 09.00 & 2,04 & 20 & 256,224 \\
\hline & & 12.00 & 2,04 & 20 & 256,224 \\
\hline & & 15.00 & 2,04 & 20 & 256,224 \\
\hline \multirow{3}{*}{9} & \multirow{3}{*}{$\begin{array}{c}\text { Sabtu } \\
(3-09-2016)\end{array}$} & 09.00 & 2,04 & 20 & 256,224 \\
\hline & & 12.00 & 2,04 & 20 & 256,224 \\
\hline & & 15.00 & 2,04 & 20 & 256,224 \\
\hline \multirow{3}{*}{10} & \multirow{3}{*}{$\begin{array}{c}\text { Minggu } \\
(4-09-2016)\end{array}$} & 09.00 & 2,04 & 20 & 256,224 \\
\hline & & 12.00 & 2,04 & 20 & 256,224 \\
\hline & & 15.00 & 2,04 & 20 & 256,224 \\
\hline \multirow{3}{*}{11} & \multirow{3}{*}{$\begin{array}{c}\text { Senin } \\
(5-09-2016)\end{array}$} & 09.00 & 2,04 & 20 & 256,224 \\
\hline & & 12.00 & 2,04 & 20 & 256,224 \\
\hline & & 15.00 & 2,04 & 20 & 256,224 \\
\hline
\end{tabular}

\section{Tahanan Jenis Tanah}

Setelah mendapatkan nilai tahanan jenis tanah diarea Program Studi Teknik Elektro Fakultas Teknik Universitas Udayana Jimbaran Bali, maka dapat dihitung nilai tahanan pembumian tipe: single rod, multiple rod $s<\mathrm{L}$, multiple rod $\mathrm{s}>\mathrm{L}$, plate dan grid. Tahanan jenis tanah yang digunakan adalah tahanan jenis tanah terbesar yaitu 256,224 $\Omega$-meter dan jari-jari elektroda yang di gunakan adalah 0,006 meter.

\section{Sistem Pembumian Tipe Single Rod}

1. Untuk sistem single rod dengan kedalaman $\mathrm{L}=20$ meter di dapatkan hasil yaitu:

$$
\begin{aligned}
& R_{s r}=\frac{\rho}{2 \pi L}\left(\ln \frac{4 L}{a}-1\right) \\
& R_{s r}=\frac{256: 224}{2 x a: 1420}\left(\ln \frac{4 n 20}{0,006}-1\right) \\
& R_{S r}=2,04 \times 8,498022444=17,34 \Omega .
\end{aligned}
$$

Dengan penanaman sistem pembumian tipe single rod seperti yang telah dihitung diatas didapat nilai tahanan pembumian sebesar $17,34 \Omega$ pada kedalaman 20 meter belum memenuhi syarat yang ditetapkan yaitu sebesar $\leq 5 \Omega$. Dengan 
Majalah Ilmiah Teknologi Elektro, Vol. 17, No. 2,Mei - Agustus 2018

DOI: https://doi.org/10.24843/MITE.2018.v17i02.P05

cara yang sama untuk mendapatkan nilai resistansi pembumian yang sesuai dengan syarat yang ditetapkan yaitu $\leq$ $5 \Omega$, dapat dilihat pada tabel 2 .

Tabel 2. HASIL PERHITUNGAN RESISTANSI PEMBUMIAN TIPE SINGLE ROD

\begin{tabular}{|c|c|c|}
\hline$\rho(\Omega-\mathrm{m})$ & Rsr (single rod) & $\mathrm{L}(\mathrm{m})$ \\
\hline 256,224 & 224,49 & 1 \\
\hline 256,224 & 31,84 & 10 \\
\hline 256,224 & 17,34 & 20 \\
\hline 256,224 & 12,11 & 30 \\
\hline 256,224 & 9,38 & 40 \\
\hline 256,224 & 7,68 & 50 \\
\hline 256,224 & 6,53 & 60 \\
\hline 256,224 & 5,68 & 70 \\
\hline 256,224 & 5,04 & 80 \\
\hline 256,224 & 4,98 & 81 \\
\hline
\end{tabular}

Dari tabel 2. dapat diketahui bahwa untuk mendapatkan nilai resistansi pembumian $\leq 5 \Omega$ pada tanah berbatu kapur diarea Program Studi Teknik Elektro Fakultas Teknik Universitas Udayana Jimbaran Bali, diperlukan penanaman elektroda pembumian dengan kedalaman 81 meter dari permukaan tanah dengan resistansi pembumian sebesar 4,98 $\Omega$.

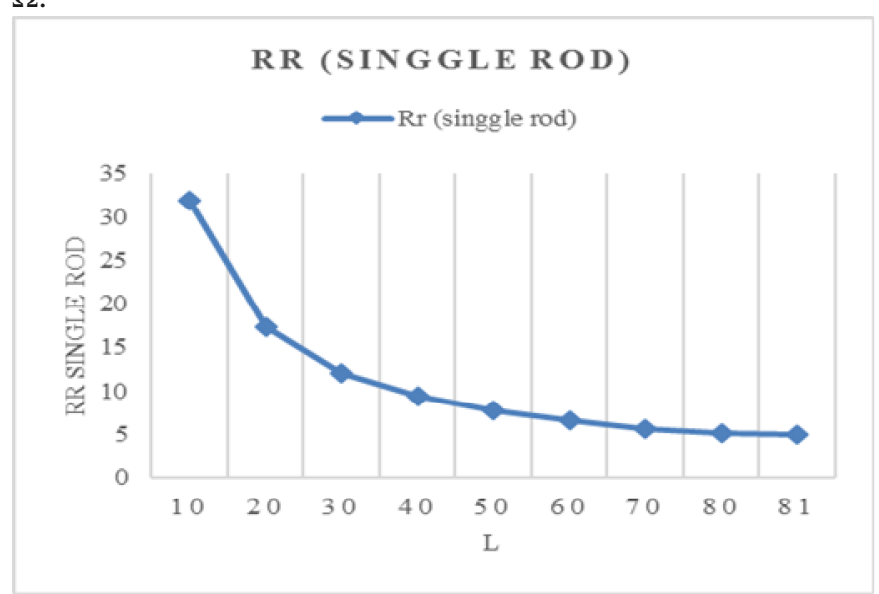

Gambar 6. Kurva Karakteristik Sistem Pembumian Single Rod

Dari gambar 6. dapat diketahui bahwa semakin dalam penanaman elektroda (L), maka nilai resistansi pembumian (Rsr) semakin kecil.

E. Sistem Pembumian Tipe Multiple Rod $s<L$

1. Sistem pembumian multiple rod dengan $\mathrm{s}<\mathrm{L}$ ( $\mathrm{s}=12$ meter dan $\mathrm{L}=15$ meter) di dapat hasil yaitu:

$$
R_{M}=\frac{\rho}{4 \pi L}=\left[\ln \frac{4 L}{a}+\ln \frac{4 L}{g}-2+\frac{z}{2 L}-\frac{g^{2}}{16 L^{2}}+\frac{s^{4}}{512 L^{4}}\right]
$$

$R_{M}=1,36[9,210340375+1,609437912-2+0,4-$

$$
0,04+0,0008]=1,36 \times 9,180578287
$$

$R_{M}=12,49 \Omega$.

Dengan sistem pembumian tipe multiple rod $s<L$ seperti yang telah dihitung didapat nilai tahanan pembumian sebesar 12,49 $\Omega$, pada kedalaman 15 meter dan jarak antar elektroda sebesar 12 meter belum memenuhi syarat yang ditetapkan yaitu sebesar $\leq 5 \Omega$. Dengan cara yang sama untuk mendapatkan nilai resistansi pembumian yang sesuai dengan syarat yang ditetapkan yaitu $\leq 5 \Omega$, dapat dilihat pada tabel 3 .

Tabel 3. HASIL PERHITUNGAN RESISTANSI PEMBUMIAN TIPE MULTIPLE ROD $\mathrm{S}<\mathrm{L}$

\begin{tabular}{|c|c|c|c|}
\hline$\rho(\Omega-\mathrm{m})$ & $\mathrm{S}(\mathrm{m})$ & $\mathrm{L}(\mathrm{m})$ & $\operatorname{Rrod} \mathrm{s}<\mathrm{L}(\Omega)$ \\
\hline 256,224 & 2 & 10 & 20,19 \\
\hline 256,224 & 12 & 15 & 12,49 \\
\hline 256,224 & 19 & 20 & 9,54 \\
\hline 256,224 & 24 & 25 & 7,81 \\
\hline 256,224 & 29 & 30 & 6,63 \\
\hline 256,224 & 34 & 35 & 5,77 \\
\hline 256,224 & 39 & 40 & 5,12 \\
\hline 256,224 & 40 & 42 & 4,90 \\
\hline
\end{tabular}

Dari tabel 3. dapat diketahui bahwa untuk mendapatkan nilai resistansi pembumian $\leq 5 \Omega$ pada tanah berbatu kapur, diperlukan penanaman elektroda pembumian dengan kedalaman penanaman 42 meter dan jarak antar elektrodra sebesar 40 meter dengan nilai resistansi pembumian sebesar $4,90 \Omega$.

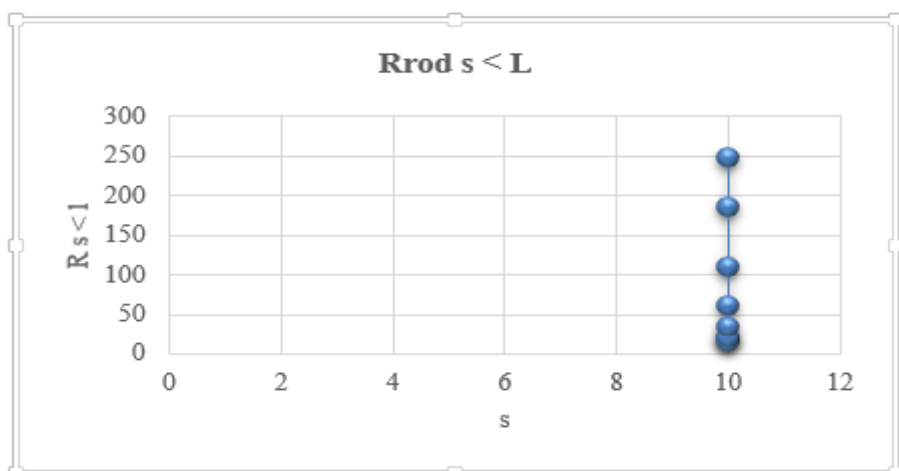

Gambar 7. Kurva Karakteristik Sistem Pembumian Multiple Rod $\mathrm{s}<$ L dengan s tetap dan L berubah-ubah

Kadek Rudi Andika : Analisis Sistem Pembumian untuk Mengamankan ...

p-ISSN:1693 - 2951; e-ISSN: 2503-2372

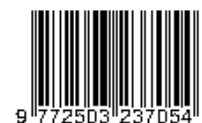




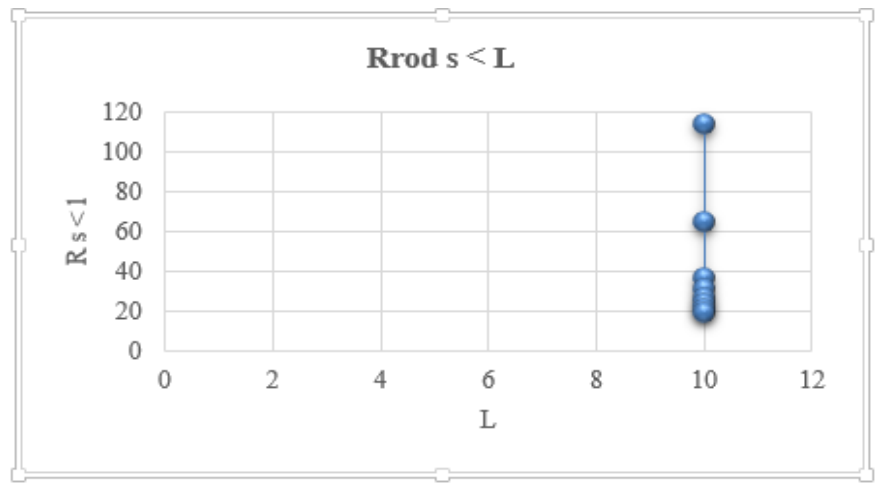

Gambar 8. Kurva Karakteristik Sistem Pembumian Multiple Rod $\mathrm{s}<\mathrm{L}$ dengan $L$ tetap dan s berubah-ubah

Dari gambar 7. dan 8. dapat diketahui bahwa dengan nilai s (jarak antar elektroda) tetap dan nilai L (kedalaman penanaman elektroda) berubah-ubah maka resistansi pembumian semakin kecil, begitu juga dengan nilai $\mathrm{L}$ (kedalaman penanaman elektroda) tetap dan nilai s (jarak antar elektroda) berubah-ubah maka resistansi pembumian semakin kecil . Dimana nilai (s) lebih kecil dari pada (L).

E. Sistem Pembumian Tipe Multiple Rod $S>L$

1. Sistem pembumian multiple rod dengan $\mathrm{s}>\mathrm{L}$ ( $\mathrm{s}=15$ meter dan $\mathrm{L}=12$ meter) didapatkan hasil sebagai berikut:

$$
\begin{aligned}
& R_{m}=\frac{A}{4 \pi L}\left[\ln \frac{4 L}{a}-1\right]+\frac{A}{4 \pi s}\left[1-\frac{Z^{2}}{3 g^{2}}+\frac{2 L^{4}}{5 s^{4}}\right] \\
& R_{m}=\frac{256224}{4 \times 214 \times 12}\left[\ln \frac{48}{0.006}-1\right]+\frac{256,224}{4 \times 2.14 \times 15}[1- \\
& \left.\frac{144}{675}+\frac{41472}{102880}\right] \\
& R_{m}=1,7[7,987196821]+1,36[1-0,21333+0,4] \\
& R_{m}=13,5782346+1,292689064=14,87 \Omega .
\end{aligned}
$$

Dengan penanaman sistem pembumian tipe multiple rod s > $L$ seperti yang telah dihitung didapat nilai tahanan pembumian sebesar $14,87 \Omega$, pada kedalaman 12 meter dan jarak antar elektroda sebesar 15 meter belum memenuhi syarat yang ditetapkan yaitu sebesar $\leq 5 \Omega$. Dengan cara yang sama untuk mendapatkan nilai resistansi pembumian yang sesuai dengan syarat yang ditetapkan, dapat dilihat pada tabel 4 .

Tabel 4. HASIL PERHITUNGAN RESISTANSI PEMBUMIAN TIPE

\begin{tabular}{|c|c|c|c|}
\hline$\rho(\Omega$ - meter $)$ & $\mathrm{S}(\mathrm{m})$ & $\mathrm{L}(\mathrm{m})$ & Rrod s > L $(\Omega)$ \\
\hline 256,224 & 10 & 2 & 65,21 \\
\hline 256,224 & 15 & 12 & 14,87 \\
\hline 256,224 & 20 & 19 & 10,11 \\
\hline 256,224 & 25 & 24 & 8,22 \\
\hline 256,224 & 30 & 29 & 6,95 \\
\hline 256,224 & 35 & 34 & 6,02 \\
\hline 256,224 & 40 & 39 & 5,33 \\
\hline 256,224 & 43 & 42 & 4,98 \\
\hline
\end{tabular}

Dari tabel 4. dapat diketahui bahwa untuk mendapatkan nilai resistansi pembumian $\leq 5 \Omega$ pada tanah berbatu kapur, di perlukan penanaman elektroda pembumian dengan kedalaman 42 meter dengan jarak antar elektrodra sebesar 43 meter dan nilai resistansi pembumian sebesar $4,98 \Omega$.

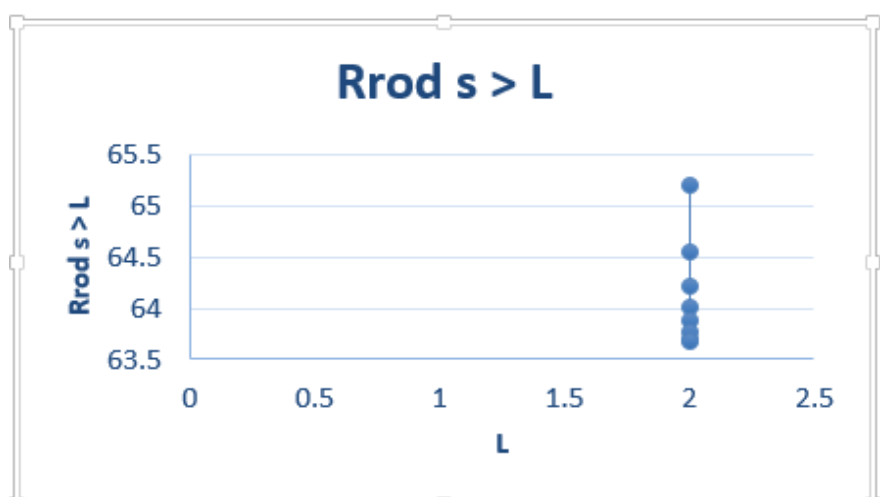

Gambar 9. Kurva Karakteristik Sistem Pembumian Multiple Rod s > L dengan L tetap dan s berubah-ubah

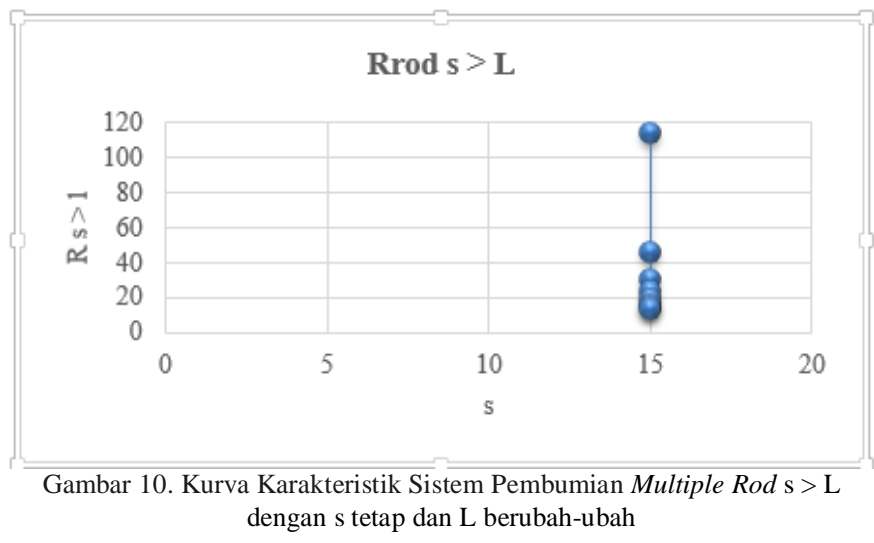

Dari gambar 9. dan 10. dapat diketahui bahwa dengan nilai s (jarak antar elektroda) berubah-ubah dan nilai L (kedalaman penanaman elektroda) tetap maka resistansi pembumian semakin kecil, begitu juga dengan nilai L (kedalaman penanaman elektroda) berubah-ubah dan nilai s (jarak antar elektroda) tetap maka resistansi pembumian semakin kecil. Dimana nilai (s) lebih besar dari pada (L).

\section{G. Sistem Pembumian Tipe Plate}

1. Untuk grounding plate dengan kedalaman $\mathrm{t}=2, \mathrm{~L}=2$ dan $\mathrm{b}=1$ meter adalah:

$$
\begin{aligned}
& R_{p}=\frac{\rho}{4,12}\left[\left(1+1,84 \frac{b}{2}\right)\right] \\
& R_{F}=\frac{256,224}{4,1 \times 2}\left[\left(1+1,84 \frac{1}{2}\right)\right]=31,2468292[1,92] \\
& R_{F}=59,99 \Omega .
\end{aligned}
$$

Dengan penanaman sistem pembumian tipe plate seperti yang telah dihitung didapat nilai tahanan pembumian sebesar $59,99 \Omega$, pada kedalaman 2 meter, dengan panjang dan lebar plate yang digunakan adalah 2 x 1 meter belum memenuhi syarat yang di tetapkan yaitu sebesar $\leq 5 \Omega$.

Untuk memperkecil nilai tahanan pembumian dapat dilakukan dengan memparalelkan elektroda plate. Maka untuk $\mathrm{R}_{\mathrm{p}}=59,99 \Omega$ dapat dihitung sebagai berikut: 


$$
\begin{aligned}
& \frac{1}{n_{\mathrm{r}}}=\frac{1}{n_{\mathrm{r}}}+\frac{1}{n_{\mathrm{r}}}+\frac{1}{n_{\mathrm{r}}}+\cdots+\frac{1}{n_{n}} \\
& \frac{1}{B_{t}}=\frac{1}{59,95}+\frac{1}{59,97}+\frac{1}{59,97}+\cdots+\frac{1}{R_{m}} \\
& \frac{1}{A_{\mathrm{T}}}=\frac{\mathrm{n}}{59,99}=\frac{59,99}{\mathrm{z}}=59,99 \\
& N_{\text {plat }}=\frac{59.59}{19,99}=3 \text { lembar }
\end{aligned}
$$

Jika $R_{\text {total }}=11,99 \Omega$, maka jumlah plate yang diperlukan adalah

$$
\begin{aligned}
& N_{\text {plat }}=\frac{R_{\text {prmbumiam }}}{R_{\text {toral }}}=\frac{59,99}{11,99} \\
& N_{\text {plat }}=5 \text { lembar }
\end{aligned}
$$

Dengan cara yang sama untuk mendapatkan nilai resistansi pembumian sebesar $\leq 5 \Omega$, dapat di lihat pada tabel 5 . sebagai berikut:

Tabel 5. HASIL PERHITUNGAN RESISTANSI PEMBUMIAN TIPE

\begin{tabular}{|c|c|c|c|c|c|c|}
\hline $\begin{array}{c}\rho(\Omega- \\
\text { meter })\end{array}$ & $\begin{array}{c}\mathrm{L} \\
(\mathrm{m})\end{array}$ & $\begin{array}{c}\mathrm{b} \\
(\mathrm{m})\end{array}$ & $\begin{array}{c}\mathrm{T} \\
(\mathrm{m})\end{array}$ & $\begin{array}{c}\text { Rplat } \\
(\Omega)\end{array}$ & banyak plat & $\begin{array}{c}\text { Rparalel } \\
(\Omega)\end{array}$ \\
\hline 256,224 & 1 & 1 & 1 & 177,48 & 2 & 88,74 \\
\hline 256,224 & 2 & 1 & 1 & 88,74 & 2 & 44,37 \\
\hline 256,224 & 1 & 1 & 2 & 119,98 & 5 & 23,99 \\
\hline 256,224 & 2 & 1 & 2 & 59,99 & 5 & 11,99 \\
\hline 256,224 & 1 & 1 & 3 & 100,82 & 8 & 12,60 \\
\hline 256,224 & 2 & 1 & 3 & 50,41 & 8 & 6,30 \\
\hline 256,224 & 1 & 1 & 4 & 91,24 & 10 & 9,12 \\
\hline 256,224 & 2 & 1 & 4 & 45,62 & 10 & 4,56 \\
\hline
\end{tabular}

Dari tabel 5. dapat diketahui bahwa untuk mendapatkan nilai resistansi pembumian $\leq 5 \Omega$ pada tanah berbatu kapur diarea Program Studi Teknik Elektro Fakultas Teknik Universitas Udayana Jimbaran Bali, diperlukan penanaman elektroda plate 4 meter dengan ukuran plate $2 \times 1$ meter dan diparalel sebanyak 10 lembar plate dengan resistansi pembumian sebesar $4,56 \Omega$.

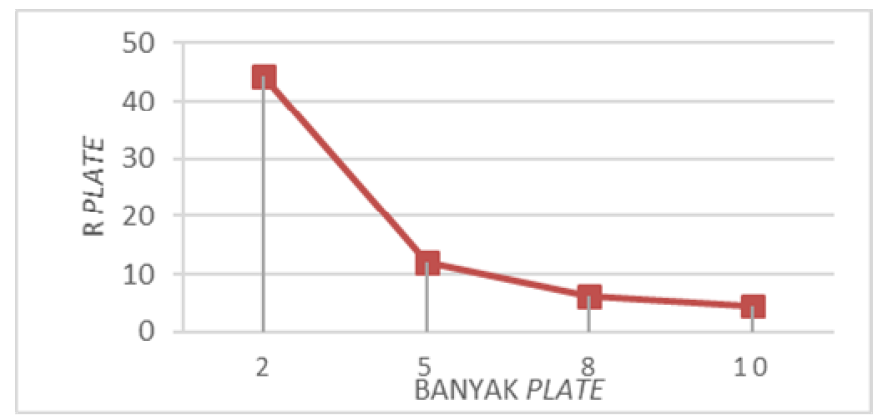

Gambar 11. Kurva Karakteristik Sistem Pembumian Tipe Plate

Dari gambar 11. dapat diketahui karakteristik sistem pembumian tipe plate bahwa semakin banyak plate yang diparalelkan maka resistansi pembumiannya semakin kecil.

\section{H. Sistem Pembumian Tipe Grid}

1. Untuk grounding grid dengan $\mathrm{L}=223, \mathrm{~h}=1$ dan $\mathrm{A}=2$ meter di dapat hasil sebagai berikut:

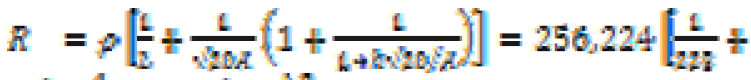

$$
\begin{aligned}
& \left.\frac{L}{x+20 y 2}\left(1+\frac{L}{L+1, \sqrt{20} 4}\right)\right] \\
& \mathrm{R}=256,224(0,004484305+0,111803399 \times \\
& \text { 1,309016994) } \\
& \mathrm{R}=38,65 \Omega \text {. }
\end{aligned}
$$

Dengan cara yang sama untuk mendapatkan nilai resistansi pembumian yang sesuai dengan syarat yang di tetapkan yaitu $\leq 5 \Omega$, dapat dilihat pada tabel 6 .

Tabel 6. HASIL PERHITUNGAN RESISTANSI PEMBUMIAN TIPE GRID

\begin{tabular}{|c|c|c|c|c|c|c|c|c|c|c|}
\hline L1 & L2 & $\begin{array}{c}\text { D1 } \\
\text { dan } \\
\text { D2 }\end{array}$ & $\mathrm{n}$ & $\mathrm{m}$ & $\mathrm{Nr}$ & $\mathrm{Pr}$ & $\mathrm{L}$ & $\mathrm{h}$ & $\mathrm{A}$ & $\begin{array}{c}\text { Rgrid } \\
(\Omega)\end{array}$ \\
\hline 1 & 1 & 0,05 & 21 & 21 & 80 & 1 & 122 & 1 & 1 & 69,86 \\
\hline 2 & 1 & 0,05 & 41 & 21 & 120 & 1 & 223 & 1 & 2 & 38,65 \\
\hline 2 & 2 & 0,05 & 41 & 41 & 160 & 1 & 324 & 1 & 4 & 21,88 \\
\hline 3 & 2 & 0,05 & 61 & 41 & 200 & 1 & 465 & 1 & 6 & 15,57 \\
\hline 4 & 3 & 0,05 & 81 & 61 & 280 & 1 & 787 & 2 & 12 & 7,84 \\
\hline 4 & 4 & 0,05 & 81 & 81 & 320 & 1 & 968 & 3 & 16 & 5,79 \\
\hline 5 & 4 & 0,05 & 101 & 81 & 360 & 1 & 1189 & 3 & 20 & 4,79 \\
\hline
\end{tabular}

Dimana: L1 dan L2 (panjang dan lebar grid) (meter)

D1 (jarak antar konduktor paralel sisi panjang)(meter)

D2 (jarak antar konduktor paralel sisi lebar) (meter) n (jumlah konduktor paralel sisi panjang)

m (jumlah konduktor paralel sisi lebar)

$\mathrm{Nr}$ (jumlah rod)

Pr (panjang rod)

h (kedalaman grid)

Dari tabel 6. dapat diketahui bahwa untuk mendapatkan nilai resistansi pembumian $\leq 5 \Omega$ pada tanah berbatu kapur disekitaran area Program Studi Teknik Elektro Fakultas Teknik Universitas Udayana Jimbaran Bali dengan metode grid diperlukan penanaman elektroda grid sedalam 3 meter dan ukuran grid 5 x 4 meter dengan panjang total konduktor Grid adalah 1189 meter dengan nilai resistansi pembumian sebesar 4,79 $\Omega$. 


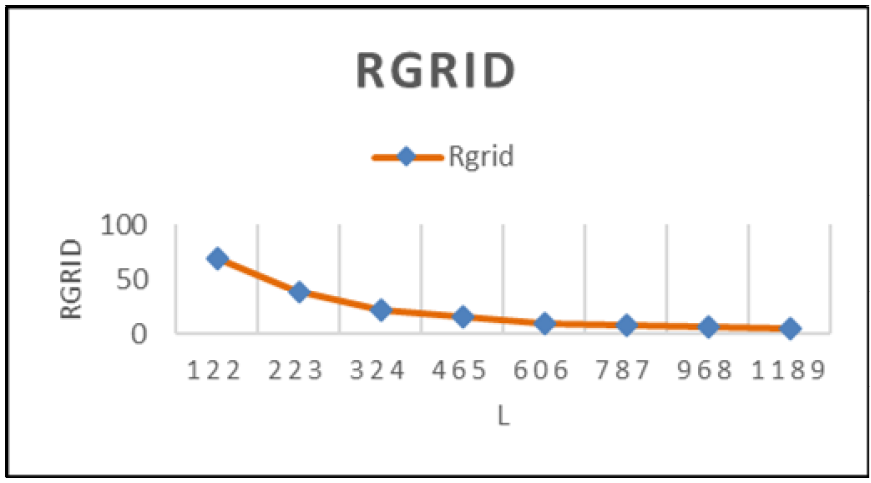

Gambar 12. Kurva Karakteristik Sistem Pembumian Tipe Grid

Dari gambar 12. dapat diketahui karakteristik sistem pembumian tipe grid yaitu semakin panjang konduktor grid (L), maka resistansi pembumiannya semakin kecil.

Untuk tanah berbatu sistem pembumian yang tepat adalah sistem pembumian tipe plate atau grid [7]. Sehingga sistem pembumian di Program Studi Teknik Elektro Fakultas Teknik Universitas Udayana Jimbaran Bali karena tekstur tanahnya berbatu kapur maka sistem pembumian yang memungkinkan dipasang adalah sistem pembumian tipe plate dengan ukuran 2x1 meter dan di paralelkan sebanyak 10 lembar plate dengan kedalaman penanaman 4 meter, resistansi pembumiannya sebesar 4,56 $\Omega$ atau sistem pembumian tipe grid dengan ukuran grid 5x4 meter dan panjang total konduktor grid 1189 meter dengan kedalaman penanaman 3 meter, besar resistansi pembumiannya sebesar $4,79 \Omega$.

\section{KESIMPULAN}

Berdasarkan hasil analisis sistem yang telah dilakukan, maka dapat disimpulkan bahwa:

1. Tekstur tanah di Program Studi Teknik Elektro Fakultas Teknik Universitas Udayana Jimbaran Bali adalah berbatu kapur. Besar resistansi pembumian pada Main Distribution Panel (MDP) sebesar $28 \Omega$. Nilai tahanan pembumian tersebut masih > $5 \Omega$. Maka perlu dilakukan pemilihan sitem pembumian dengan nilai $\mathrm{R} \leqslant 5 \Omega$.

2. Karakteristik sistem pembumian (single rod, multiple rod $s<L$, multiple rod $s>L$ grid, plate) seperti pada gambar (6), (7), (8), (9), (10),(11),(12) adalah sebagai berikut:

a. Single rod: semakin dalam penanaman elektroda (L), maka nilai resistansi pembumian (Rsr) semakin kecil. Penanaman elektroda pembumian 82 meter dari permukaan tanah, resistansi pembumian sebesar 4,98 $\Omega$.

b. Multiple $\operatorname{rod} \mathrm{s}<\mathrm{L}$ : dengan nilai (L) tetap dan nilai (s) berubah-ubah maka resistansi pembumian semakin kecil, begitu juga dengan nilai (s) tetap dan nilai (L) berubah-ubah maka resistansi pembumian semakin kecil. Dimana nilai (s) lebih kecil dari pada (L). Penanaman lektroda pembumian 42 meter dan jarak antar elektroda 40 meter, resistansi pembumian sebesar $4.90 \Omega$.

c. Multiple $\operatorname{rod} \mathrm{s}>\mathrm{L}$ : dengan nilai (s) tetap dan nilai (L) berubah-ubah maka resistansi pembumian semakin kecil, begitu juga dengan nilai (L) tetap dan nilai (s) berubah-ubah maka resistansi pembumian semakin kecil. Dimana nilai (s) lebih besar dari pada (L). Penanaman elektroda pembumian 42 meter dan jarak antar elektrodra 43 meter, resistansi pembumian sebesar $4.98 \Omega$.

d. Plate: semakin banyak plate yang di paralelkan maka nilai resistansi pembumian semakin kecil. Ukuran plate 2x1 meter dan di paralel sebanyak 10 lembar plate dan kedalaman penanaman 4 meter, resistansi pembumian sebesar 4,56 $\Omega$.

e. Grid: semakin panjang konduktor grid (L), maka resistansi pembumiannya semakin kecil. Dengan ukuran grid $5 \times 4$ meter, panjang total konduktor grid adalah 1189 meter dan kedalaman penanaman 3 meter, besar resistansi pembumian $4,79 \Omega$.

3. Berdasarkan hasil penelitian yang telah dilakukan, sistem pembumian yang digunakan di Program Studi Teknik Elektro Fakultas Teknik Universitas Udayana Jimbaran Bali adalah tipe single rod dengan nilai resistansi pembumiannya $28 \Omega$. Besar nilai resistansi pembumian tersebut belum memenuhi syarat yang ditetapkan sebasar $\leq$ $5 \Omega$. Jadi sistem pembumian yang direkomendasikan dipasang dengan nilai resistansi pembumian sesuai dengan syarat yang ditetapkan adalah sistem pembumian tipe grid dengan resistansi pembumian sebesar 4,79 $\Omega$ atau plate

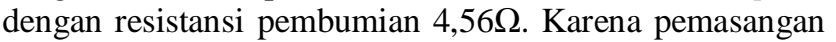
sistem pembumian tipe grid atau plate tidak terlalu dalam dibandingkan tipe single rod, multiple rod $s<L$ dan multiple rod $s>L$, mengingat tekstur tanah berbatu kapur.

\section{REFERENSI}

[1] Arismunandar, A. Kuwahara, S. 2004. Buku Pegangan Teknik Tenaga Listrik Gardu Induk. Jakarta: PT. Pradnya Paramita.

[2] Badan Syaratdisasi Nasional. 2011. Persyaratan Umum Instalasi Listrik (PUIL 2011). Jakarta: Erlanga.

[3] Janardana, IGN. 2005. Pengaruh Umur Pada Beberapa Volume Zat Aditif Bentonit Terhadap Nilai Tahanan Pentanahan. Jurnal Teknologi Elektro vol.4 (2) 2005. Denpasar: Universitas Udayana.

[4] IEEE Std 80 - 1986. IEEE Guid Safety in AC Substation Grounding. New York.

[5] Pfeiffer, JC. 2001. Principles of Electrical Grounding. Memphis: Christian Brothers University.

[6] Lee, CH. 1999. A Comparison of IEC 479-1 and IEEE Std 80 on Grounding Safety Criteria. Proc. Natl. Sci. Counc. ROC Vol.23 (5) 1999. Taiwan: Department of Electrical Engineering I-Shou University Kahhsiung.

[7] Hutauruk, TS. 1987. Pentanahan Netral Sistem Tenaga Dan Pentanahan Peralatan. Jakarta: Erlangga.

[8] Suswanto, D. 2009. Sistem Distribusi Tenaga Listrik. Edisi Pertama. Padang: Universitas Negeri Padang.

[9] Janardana, IGN. 2005. Perbedaan Penambahan Garam Dengan Penambahan Bentonit Terhadap Nilai Tahanan Pentanahan Pada Sistem Pentanahan. Jurnal Teknologi Elektro vol.4 (1) 2005. Denpasar: Universitas Udayana.

[10] IEEE Std 142TM - 2007. IEEE recommended practice for grounding of industrial and commercial power system. New York.NN. 2007.

[11] IEEE Syarat 80 - 2000. IEEE Guid for Safety in AC Substation Grounding. New York.

[12] Pabla, AS. 1994. Sistem Distribusi Daya Listrik. Jakarta: Erlangga. 